\title{
Do you read me? Associations between perceived teacher emotional support, reader self-concept, and reading achievement
}

\author{
Maria Therese Jensen $^{1}$ (D) Oddny Judith Solheim ${ }^{1} \cdot$ Ella Maria Cosmovici Idsøe $^{2}$
}

Received: 22 January 2018 / Accepted: 2 November 2018 / Published online: 14 January 2019

(C) The Author(s) 2019

\begin{abstract}
The aim of the current study was to examine the associations among perceived teacher emotional support, reader self-concept, and reading achievement in a sample of children $(n=2888)$ at the end of first grade. Structural equation modelling revealed significant relations between perceived teacher emotional support and reader self-concept and between reader self-concept and reading achievement. No direct association was found between perceived teacher emotional support and reading achievement. However, we found that reader self-concept mediated the association between perceived teacher emotional support and reading achievement. Conclusively, teachers should have in mind that supporting children emotionally might contribute to both higher reading self-concept and higher reading achievement.
\end{abstract}

Keywords Reader self-concept · Emotional support · Reading achievement · Structural equation modelling $\cdot$ Mediation

\section{Introduction}

Among various academic skills, reading is the most important learning activity in which children engage during their first years at school (Chapman et al. 2000), as the ability to read is fundamental for academic achievement and success (Perfetti and

Maria Therese Jensen

maria.t.jensen@uis.no

Oddny Judith Solheim

oddny.j.solheim@uis.no

Ella Maria Cosmovici Idsøe

e.m.c.idsoe@naturfagsenteret.no

1 Norwegian Reading Centre, National Centre for Reading Education and Research, University of Stavanger, 4036 Stavanger, Norway

2 The Norwegian Centre for Science Education, University of Oslo, 0316 Oslo, Norway 
Curtis 1986). Children's early experiences of learning to read influence the development of self-perceptions related to reading. Poor performance in reading may become disabling and interfere with academic progress in school (Perie et al. 2005).

One psychological construct that has emerged as a highly effective predictor of students' academic achievement, including reading, is self-concept (Byrne 1996; Marsh 1993; Marsh and Craven 2006). Self-concept has been defined as persons' self-perceptions that are formed through experiences and interpretations of their environment (Shavelson et al. 1976). Self-perceptions and self-concept are often used interchangeably in the literature. For clarification we will primarily use the term self-concept in the current study.

Whether self-concept is considered a multidimensional rather than a unidimensional factor varies across sub disciplines in psychology and across social science disciplines (Marsh and Craven 2006). The multidimensional nature of self-concept is bounded in that how individuals perceive themselves in one area of their life may be unrelated to how they view themselves in another. For instance, the same individual can have different perceptions of themselves with regards to being a friend, a student, and/or a son/daughter, among other roles (Pajares and Schunk 2001). Several studies have provided support for the multidimensional nature of self-concept (Bong and Clark. 1999; Marsh 1993), and in general self-concept becomes increasingly multifaceted as the individual moves from infancy to adulthood (Marsh and Shavelson 1985). A strong support for the existence of self-concept as a multidimensional aspect comes from educational psychology and its focus on academic self-concept (Marsh and Martin 2011). Moreover, it has been suggested that even academic selfconcept consists of multiple facets related to various subject areas as math, science etc. (Shavelson et al. 1976), and in the context of reading the facet of academic selfconcept can be referred to as reader self-concept (Chapman et al. 2000).

With regard to reader self-concept, stable patterns of competence or difficulties in reading seem to take a couple of years to display, whereas self-concept related to these achievements takes somewhat longer to stabilize (Chapman and Tunmer 1995; Stipek 2002). However, evidence suggests that for some children, consistent experiences regarding difficulties or proficiency in reading are already present from the outset of schooling (Chapman et al. 2000; Spear-Swerling and Sternberg 1996; Walgermo et al. 2018). Chapman et al. (2000) concluded from their study that previous research has underestimated the rapid manifestation of self-concept related to reading achievements. Spear-Swerling and Sternberg (1996) stated that when children first start to experience negative expectation and low motivation, they are more likely to experience increased difficulty with proficient reading. Thus, it is essential to prevent children from going into negative loss spirals. Based on the above, and the significance of reading achievement for academic achievement, it seems crucial to learn more about how factors in the child's classroom setting might influence the association between reader self-concept and reading skills already during the first years of school.

In general, the study of predictors of motivation and performance in school has followed two parallel traditions (Furrer and Skinner 2003). The first tradition has been concerned with the association between children's self-concept and performance in school (e.g., Eccles et al. 1993; Stipek 2002), whereas the second tradition 
has been more concerned with the significance of social aspects in the learning environment, such as relationships with parents (Steinberg et al. 1995), peers (Hymel et al. 1996), and teachers (Stipek 2002). Lately, however, these two traditions of self-concept and interpersonal relations have approached each other, and the main idea is now that when children interact socially, they construct generalized beliefs about the self (Furrer and Skinner 2003). For instance, when children's relationships with significant adults are caring and supportive, they are more likely to internalize the goals and expectations that the significant adult value compared to when these relations are harsh and critical (see Grusec and Goodnow 1994). Hence, significant adults have the potential to create optimal contexts where learning can happen (Wentzel 1999).

One very significant adult for children at school entry is naturally the teacher, and it is well recognized that the quality of social interaction between teacher and student is related to both academic and social outcomes (Mashburn et al. 2008; Stipek and Byler 2004). Moreover, earlier research found that teacher-child relationships are even stronger predictors of achievement than insecure maternal attachments and relations with peers (O'Connor and McCartney 2007). Thus, one approach to understanding how schooling relates to differences in achievement among children is the assessment of variation in the nature of teacher's interactions with students (Burchinal et al. 2008). Researchers have emphasized the significance of closeness and caring in the student-teacher relationship (Goldstein 1999; Lynch and Cicchetti 1997; Pianta 1994; Wentzel 1997), and it has even been found that students considered functionally at risk obtained achievement scores similar to their low-risk peers when they experienced strong emotional support from teachers (Hamre and Pianta 2005). Emotionally supportive teachers are viewed as warm and kind, sensitive to the emotional needs of the child, and thoughtful about the way they respond to children. (Pianta et al. 2008b).

To our knowledge, previous studies have not investigated the association of children's perceived emotional support from teachers with students' reader self-concept and its relation to reading achievement in particular. Thus, in the current study, we wanted to investigate associations between children's perceived emotional support from teacher, reader self-concept and reading achievement. Considering the significance of early reading for further academic achievement, it is important to learn more about the ways in which the child's perceived emotional support from the teacher might reinforce children's reading achievement during the early school years.

\subsection{Theoretical perspective}

It is reasonable to assume that social-motivational processes have the most proximal social influence on academic outcomes (Wentzel 1999). Thus, socialisationmotivational processes were considered as the theoretical basis for the present study (Weiner 1993). Motivational processes can be defined as "A set of interrelated beliefs and emotions that direct behavior" (Wentzel 1999, p. 76). An important assumption within socialisation processes is that individuals construct beliefs about 
themselves as they experience and interact with others (Wentzel 1999). The current study assumes that the social world of students influences academic outcomes primarily through intrapersonal and psychological processes (Wentzel 1999). The teacher is an essential part of children's social context in early school years. In middle school, students' perceptions that teachers care about them have been related to positive aspects of student motivation, such as pursuit of social and academic goals, proficiency orientations toward learning, and academic interest (Wentzel 1997). In line with the theory of social-motivational processes, this implies that the child's perception of the social relation with the teacher will be associated with his/her selfconcept, and subsequently to his/her academic outcomes.

\subsection{Self-concept and academic achievement}

Academic self-concept refers to individuals' knowledge and perceptions of themselves in an academic context (Byrne 1984; Wigfield and Karpathian 1991). Several review studies have confirmed that academic outcomes relate systematically to academic self-concept (Byrne 1996; Guay et al. 2003; Marsh 1993; Marsh and Craven 2006). Additional studies have reported the relations between academic selfconcept, student's intrinsic motivation, effort, and help seeking behavior (Skaalvik and Skaalvik 2013).

A question often asked is whether academic self-concept or academic achievement "comes first". The causal determination of self-concept as a predictor over academic skills has often been referred to as the self-enhancement model (Chapman and Tunmer 1997). It has been found that students' grades were significantly affected by their academic self-concept in previous years (Marsh 1990). Researchers adopting the enhancement perspective believe that positive self-concept results in better academic functioning. Thus, the effort of educational interventions should be devoted to augmenting students' perceptions of the self (Bong and Clark 1999). Evidence for the self-enhancement model has also been found in longitudinal studies (Marsh 1990). The other perspective taken is a "skill-developmental model," which proposes that academic self-concept is a consequence rather than a cause of students' academic achievement (Calsyn and Kenny 1977; Scheirer and Kraut 1979). However, the results from several studies revealed that the causal relation between self-concept and achievement changes with age, implying that the validity of the self-enhancement model and the skill-developmental model might depend on the age of the children studied. Academic achievement demonstrated causal effect on academic self-concept of young children in longitudinal studies (Chapman and Tunmer 1997; Helmke and van Aken 1995), implying that self-concept manifests itself in response to children's perceptions of the mastery of their academic skills and teachers' interpretation of children's academic performance (e.g., Helmke and van Aken 1995; Skaalvik and Hagtvet 1990).

In the current study we acknowledge that both the self-enhancement model and the skill-developmental model are valid perspectives when studying associations between reader self-concept and reading achievement. However, considering the children in our sample had attended school for nearly a year, it seems obvious that 
they have already developed some degree of self-concept related to their reading skills, which might again have an influence on reading achievement. Consequently, we considered the self-enhancement model to be the most appropriate for our study.

In the current study we focus specifically on accuracy and fluency as aspects of reading achievement, and not reading comprehension. Reading comprehension takes somewhat longer to develop, and due to the young age of the students in our sample, we considered it most relevant to include accuracy and fluency as measures of students reading achievement.

Moreover, we consider self-concept to be a multidimensional aspect and focus specifically on reader self-concept. Studies have demonstrated associations between reader self-concept and reading achievement (Chapman and Tunmer 1997; Chapman et al. 2000; Walgermo et al. 2018). Thus, we expect to see a positive association between reader self-concept and reading achievement and propose the following hypotheses:

Hypothesis 1 Self-concept is positively related to reading achievement

\subsection{Perceived teacher emotional support as predictor of self-concept and academic achievement}

The lack of emotional support may have negative consequences for the social development of children (Pianta et al. 2008a; Stuhlman and Pianta 2009), whereas strong emotional support seems to strengthen children's social skills (Hughes et al. 2008). In addition to being of significance for the child's social development, a strong evidence suggests that emotional support from the teacher is associated with children's academic achievement and learning. Several longitudinal studies have demonstrated positive relations between teacher emotional support and academic achievement (Hamre and Pianta 2001; Hughes et al. 2008; Ladd et al. 1999; Pianta and Stuhlman 2004). One explanation for this could be that when students perceive that the environment is safe through the teacher's sensitive responses, students are more likely to take chances in their learning (Hamre and Pianta 2007). Moreover, emotionally supportive teachers support children's independence and expression of ideas (Bredekamp and Copple 1997; Kern and Clemens 2007).

Emotional support from teachers was also associated with children's verbal and reading achievement (Curby et al. 2013a, 2009; Furrer and Skinner 2003; Hamre and Pianta 2001, 2005; Hughes et al. 2008; Rudasill et al. 2010). Based on the above, we proposed the following hypothesis:

Hypothesis 2 Perceived teacher emotional support is positively related to reading achievement.

To our knowledge, associations between perceived emotional support from teachers and reader self-concept of children during the first year of school have not been studied previously. However, former studies have suggested that the teacher-child relationship can affect the child's self-concept and expectations regarding academic 
achievement (e.g., Harter and Connell 1984; Pallas et al. 1987). Pianta et al. (1995) found an association between the quality of children's relationship with their teacher and the quality of both their current and future school performance. Based on the abovementioned social-motivational theory, we expected emotional support from teachers to be associated with reader self-concept. Thus, we suggested the following hypothesis:

Hypothesis 3 Perceived teacher emotional support is positively related to reader self-concept.

In addition to investigating how perceived emotional support from teacher relates directly to reading achievement, we were also interested in investigating whether perceived emotional support from teachers might be associated with reading achievement indirectly through reader self-concept. Based on social-motivational theory predicting an association between perceived teacher emotional support and reader self-concept (Wentzel 1997) as well as the association between reader selfconcept and reading achievement (Byrne 1996; Guay et al. 2003; Marsh 1993; Marsh and Craven 2006), it was considered plausible to test for mediation as well. Accordingly, the following hypothesis was proposed:

Hypothesis 4 Reader self-concept will partially mediate the association between perceived teacher emotional support and reading achievement.

Figure 1 depicts a working model of the expected associations in the present study. The model reflects the hypotheses specified and discussed above.

\section{Method}

\subsection{Context}

The specific study aims to explore how perceived teacher emotional support relates to reader self-concept and reading performance among children at the end of first grade. Data applied in the current study is part of a large Norwegian research project, including 150 schools from 53 municipalities in 9 counties in Southern Norway (for more information about the project, see Solheim et al. 2017). The Norwegian Social Science Data Service which is a third party ethical oversight agency in

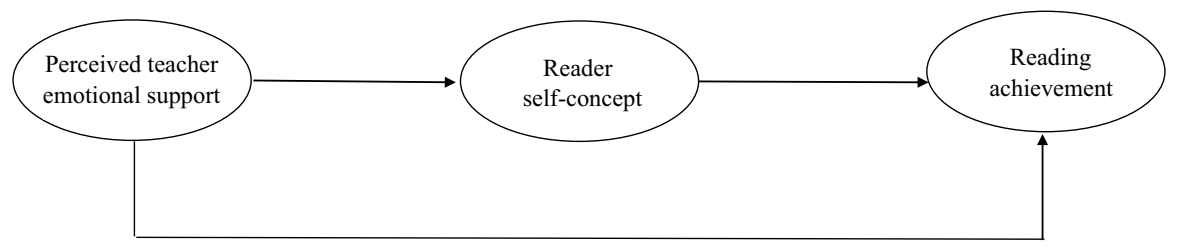

Fig. 1 Theoretical model of the study 
Norway, has approved the study. Moreover, the project follows the Ethical guidelines developed by the National Committee for Research Ethics in the Social Sciences and Humanities.

\subsection{Sample}

The sample in the current study comprised first graders who started school in August 2016. Data were collected during May and June 2017, at the end of first grade. Initially, 6014 students were enrolled in the study, and written parental consent was achieved from $95.2 \%$ of the sample, yielding a total sample of 5830 students distributed to 300 classes at 150 different schools. However, due to differences in teacher ratio in the different classes which might have an effect on the students' responses to teacher emotional support, we found it necessary to solely include classes with one teacher. In total this entailed a sample of 2888 students distributed to 150 classes at 150 different schools. Of the students in our sample, $47.6 \%$ were girls, and $52.4 \%$ were boys. The average age of the students at the time when the data were collected was 7 years old.

\subsection{The measurement of perceived teacher emotional support in the current study}

Several studies have demonstrated an association between teacher emotional support and reading (e.g., Perry et al. 2007; Rimm-Kaufman and Chiu 2007; Rudasill et al. 2010). However, when measuring teacher emotional support among children, previous research had collected the data primarily from classroom observations (e.g., Curby et al. 2013a, b, 2009; Hamre and Pianta 2005; Merritt et al. 2012; Perry et al. 2007; Rudasill et al. 2010) or teacher ratings of students (Hughes et al. 2008; O'Connor and McCartney 2007). Although most studies have relied on observational data when studying teacher emotional support, it is important to bear in mind that student perceptual measures can have some advantages over observational data. While observational data are usually limited to a very small number of lessons, perceptual measures from students are based on students' experiences over many lessons (Fraser 1989). Moreover, perceptual measures involve the judgements from all students in a class, not solely from a single observer (Fraser 1989). Student reports have the potential to add a unique perspective to the understanding of how teacher-student interaction unfolds in the classroom (Downer et al. 2015). Downer and colleagues (2015) applied perceptual student measures for measuring emotional support among fourth-and fifth-grade students, and found that student report data were associated with reading proficiency, supporting the use of student perceptual measures. Finally, from a phenomenological perspective, individual student's ratings can be considered the most appropriate sources of data, as it is likely that a student's behavior is more affected by his or her interpretation of the classroom context than by any objective indicator of that context (Lüdtke et al. 2009). Thus, in the current study we base our data on teacher emotional support on students' perceptions. 


\subsection{Teacher emotional support and level of analysis}

When studying students' perceptions of their learning environment, the level of analysis is crucial (Raudenbush and Bryk 2002). At first glance, teacher emotional support relates to the individual student's perception of closeness to his/her respective teacher. On the other hand, one could also argue that teacher emotional support consists of shared perceptions nested within different classes. Thus, one additional question we raise in our study is which level is the most appropriate when studying teacher emotional support. To our knowledge, perceptual measures of emotional support have not been applied in previous studies on such young children; thus, drawing from previous research was therefore limited. However, when looking at the theory on emotional support, it has been stated that the nature and quality of the relation between the teacher and child, just like that between the parent and child, varies (Pianta et al. 1995). Teachers approach children differently, and while teachers develop strong emotional attachment to some children, they may have difficulty getting close to other children (Pianta et al. 1995). Moreover, Skaalvik and Skaalvik (2013) pointed out that students in the same school or even the same class are often treated differently. Therefore, they do not experience the same educational context. Several previous studies have found that only a small amount of variability in students' reports on teacher emotional support could be attributed to the classroom level (e.g., Bliese 2000; Downer et al. 2015; Marsh et al. 2012). This approach supports the analysis of teacher emotional support at the individual level.

Another factor that should be considered when determining the level of analysis is item wording, as item wording can play a role in determining how much variation in student reports of classroom interaction is attributed to the between versus within levels (Wagner et al. 2013). Downer et al. (2015), stated that individually rated items will most probably lead to individual variation rather than between class variation. The items used to measure teacher emotional support in the current study were specifically concerned with the individual student's perception of how the teacher treats him/her and less concerned with the individual student's perception of emotional climate in the class overall. Thus, the wording of items supports the analysis of teacher emotional support at the individual level. It is worth mentioning that asking younger children to average across all of their classmates is potentially a cognitively challenging task, as young children are more likely to focus on their own individual experiences (Downer et al. 2015). Thus, according to Downer and colleagues (2015), children at a young age might have difficulties taking a "bird's eye view" of the classroom, reporting on more general feature of the classroom which lies beyond their personal experience. Consequently, based on the young age of our study sample, we considered individually based items as being more appropriate when measuring teacher emotional support.

Lüdtke et al. (2009) recommended that in addition to identifying the theoretically appropriate level of analysis, the psychometric properties of ratings should also be identified. Thus, before making the final decision on whether to conduct analysis at the class or individual level, we also calculated the intraclass correlations (ICCI and ICC2) and design effects for perceived teacher emotional support. The results of these analyses are reported in the results section. 


\subsection{Procedure}

All children were assessed on various measures related to reading achievement, reader self-concept, and teacher emotional support. The students were assessed individually by a trained research assistant at their respective school, in a private location outside their classroom. All research assistants had a commenced or completed a degree in teaching or psychology, received $8 \mathrm{~h}$ of training and were certified in administrating the assessment battery. The research assistants were issued with a written test manual, and all tests and questionnaires were administered scored and recorded on tablet computers.

\subsection{Scales and measures}

The factor referred to as reading achievement was measured by total scores on two tests related to reading accuracy and reading fluency (Cronbach's alpha $=.70$ ). Reading accuracy was measured by asking students to read 36 familiar words presented on the tablet one at a time. The items were taken from (Seymour et al. 2003). The word list comprised familiar high frequency words that were originally sampled from reading materials used in early stages of primary schooling. The words included content words (principally imaginable nouns) and function words (grammatical morphemes) of varying morphological complexity, including diacritics, multi-letter graphemes, and irregularities. Pilot testing indicated that students were unlikely to manage the test after six subsequent errors. Thus, after six subsequent errors the test was discontinued. We calculated the raw sum scores for the 36 items (maximum score: 36). To measure word reading fluency, students were administered a Norwegian version Test of Word Reading Efficacy (TOWRE) (Torgesen et al. 1999). TOWRE consists of two subtests. In the current study we administered Scheme A from The Sight-Word Efficiency subtest. The test assesses the child's ability to recognize and read as many words as possible in $45 \mathrm{~s}$. The words were presented as a list of words on a paper sheet. The research assistant registered the number of correct read words on the tablet.

Reader self-concept was measured by 4 items adapted from Eccles, Wigfield, Harold, and Blumenfeld (1993). Example of items include: "Do you think reading is difficult?", and "How good are you in reading compared to your classmates?" (Cronbach's alpha $=.67)$. Students responded on a 5-point Likert scale $(1=$ not good at all; $5=$ very good) indicated by various smileys. The gloomiest smiley indicated the most negative response (e.g., "I am not good at all"/“It is very difficult") while the smiley with the biggest smile indicated the most positive response (e.g., "I am very good"/"It is not hard at all"). Prior to the questions, the research assistant explained the task and reassured the students that their teachers and parents would not be informed of their answers and that it was important that they answered the questions as honestly as possible. The research assistant read each question and response alternative aloud, and the child responded by pressing one of the five smileys on the tablet. 
(Perceived Teacher) Emotional support was measured by 4 items adapted from The Classroom Assessment Scoring System-Student Report (Downer et al. 2015). The four items (Cronbach's alpha .63), were developed to capture positive climate and teachers' sensitivity. Positive climate reflects the overall emotional tone of the classroom and the connection between teachers and students (e.g., Do you feel the teacher cares about you?), whereas teacher sensitivity encompasses teachers' responsivity to students' needs and awareness of students' level of academic and emotional functioning (e.g., Will the teacher help you if you have problems?). To reduce cognitive response bias, items were altered from statements to questions (Bentler et al. 1971). The research assistant introduced the task by stating that the questions pertained to the teacher(s) who taught them in Norwegian lessons, and ensured the students that nobody else would see their answers. The research assistant then read each item aloud, and the students responded by pressing one of the five smileys on the tablet, corresponding to a 5-point scale ranging from "never" to "always." The saddest smiley indicated the most negative response, whereas the happiest smiley indicated the most positive response.

\subsection{Statistical analysis}

First, $I C C(1)$ and $I C C(2)$ for perceived teacher emotional support were calculated in order to determine the level of analysis. The $I C C(1)$ indicates the degree to which class belongingness affect students' ratings of teachers' emotional support, whereas the $I C C(2)$ provides an estimate of the reliability of the class-mean ratings (Lüdtke et al. 2009). ICC(2) values between .70 and .85 indicate acceptable reliability values (LeBreton and Senter 2008; Lüdtke et al. 2006). Second, we calculated the design effect. The design effect is an estimate of the multiplier that needs to be applied to the standard error to correct for the negative bias resulting from nested data (Peugh 2010). Design effects above 2 indicate a need for either the correction of standard errors or multilevel modelling (Muthen and Satorra 1995). Third, to validate the model shown in Fig. 1, we conducted confirmatory factor analysis (CFA) with maximum likelihood estimation using AMOS version 25.0 (Arbuckle 2014). Confirmatory factor analysis (CFA) is a statistical technique used to verify the factor structure of a set of observed variables. CFA makes it possible to test the relationship between observed variables and their underlying latent constructs. Each indicator was assigned to the measurement instrument to which it originally belonged. Fourth, structural equation modelling (SEM) was applied to test the structural model of the relationships among teacher emotional support, reader self-concept, and reading achievement. The advantage of utilizing SEM rather than linear regression is that it is possible to analyse a set of regression equations simultaneously while at the same time controlling for measurement error. Fifth, to test the significance of the mediating effect of reader self-concept on the relation between perceived teacher emotional support and reading achievement, we applied the bias-corrected bootstrap mediation in AMOS version 25.0. The bias-corrected bootstrap approach has been suggested as the most optimal method, as it controls for skewness in the population (MacKinnon et al. 2004). Specifically, 1000 bootstraps and $95 \%$ confidence intervals 
were applied. Finally, to determine the means, standard deviations, correlations, and internal consistency of measures, Statistical Programs for Social Scientists (SPSS), version 25 , was utilized.

CFA and SEM rely on several statistical tests to determine the model fit to the data. In the current study, we evaluated the comparative fit index (CFI), root means square error of approximation (RMSEA), normative fit index (NFI), and incremental fit index (IFI). A CFI value of .90 or greater and RMSEA value of .06 or less indicate acceptable model fit (Hu and Bentler 1999). Recommended values of NFI and IFI are .90 or above (Bentler and Bonnet 1980).

\section{Results}

\subsection{Preliminary analysis}

The $I C C(1)$ and $I C C(2)$ for perceived teacher emotional support were calculated based on the aggregated ratings in each of the 150 classes. The results showed that $I C C(1)$ for perceived teacher emotional support was .08, whereas the $I C C(2)$ was .64 . This implies that only $.08 \%$ of the variance in student's ratings on teacher emotional support can be attributed to the fact that students are nested in different classes. Moreover, the $I C C(2)$ value of .64 in the current study is slightly below the recommended threshold (LeBreton and Senter 2008; Lüdtke et al. 2006). Second, we calculated the design effect, which was estimated to be 1.44 . The value indicates that the clustering in the data at class level does not need to be considered (Muthen and Satorra 1995). Third, to validate our measurement concepts and to test whether our data fit the hypothesized measurement model, confirmatory factor analysis (CFA) was conducted. The concepts were considered latent factors, which explain the variances in their associated manifest variables. The results indicated that the measurement model with data at the individual level provided good fit to the data $\left(\chi^{2}=167.710 ; d f=32, \mathrm{RMSEA}=.038, \mathrm{CFI}=.970 ; \mathrm{NFI}=.964, \mathrm{IFI}=.970\right)$. Thus, the overall findings supported the need to precede with further analysis, applying the data at the individual level.

\subsection{Descriptive statistics and internal consistency reliability}

Means, standard deviations, correlations, and internal consistency reliabilities (Cronbach's alpha) were computed for all measurement concepts. As shown in Table 1, the Cronbach's alpha scores ranged from .63 to .70. Two of our measurements concepts (perceived teacher emotional support and reader self-concept) had alpha values slightly below the general norm of .70 (Nunnally 1978). However, the application of Cronbach's alpha to measure internal consistency has challenges (see for instance Barbaranelli et al. 2015; Sijtsma 2009), and it has been suggested that confirmatory factor analysis (CFA) in structural equation modelling provides more rigorous analysis of model power, determining construct and content validity more 
Table 1 Means (M), standard deviations (SD) Cronbach's $\alpha$ (on the diagonal) and correlations for the study variables

\begin{tabular}{llrllll}
\hline Variable & $n$ & \multicolumn{1}{c}{$M$} & $S D$ & 1. & 2. & 3. \\
\hline 1. Emotional support & 2786 & 4.44 & 0.66 & $\mathbf{( . 6 3 )}$ & & \\
2. Reader self-concept & 2799 & 3.96 & 0.72 & $.21^{*}$ & $\mathbf{( . 6 7 )}$ & \\
3. Reading achievement & 2798 & 25.85 & 5.92 & $.10^{*}$ & $.33^{*}$ & $\mathbf{( . 7 0 )}$ \\
\hline${ }^{*} p<.01$ & & & & & &
\end{tabular}

precisely (Jöreskog 1993; Loehlin and Beaujean 2016). Thus, we decided to rely primarily on this analysis to validate our measurement concepts.

\subsection{Testing of structural relationships}

The next step involved the development of a structural model. The results shown in Fig. 2 indicate that the suggested structural model fitted the data well $\left(\chi^{2}=167.710\right.$; $d f=32$; RMSEA $=.038, \mathrm{CFI}=.970, \mathrm{NFI}=.964, \mathrm{IFI}=.970) . \mathrm{SEM}$ analysis revealed a positive relationship between reader self-concept and reading achievement $(\beta=.47, p<.001)$, supporting Hypothesis 1 . Moreover, we expected to find a positive relation between perceived teacher emotional support and reading achievement. However, this association proved not to be significant in our model, and Hypothesis 2 was therefore not supported. As expected, a positive relation was found between perceived teacher emotional support and reader self-concept $(\beta=.32, p<.001)$, supporting Hypothesis 3.

Finally, we also wanted to test whether reader self-concept mediated the relation between perceived teacher emotional support and reading achievement. To investigate the indirect effect of perceived teacher emotional support on reading outcomes, we applied the bias-corrected bootstrap test of mediation. The results demonstrated that reader self-concept mediated the relation between perceived teacher emotional support and reading outcomes $(\beta=.15,95 \%$ [CI .11, .20] $p<.001)$. Moreover, when reader self-concept was omitted from our model, results revealed a significant association between perceived teacher emotional support and reading achievement $(\beta=.15, p<.001)$, indicating that the relation between perceived teacher emotional support and reading achievement was fully mediated by reader self-concept. The fit of the mediation model was found to be generally satisfactory $\left(\chi^{2}=172.916 ; d f=32\right.$;

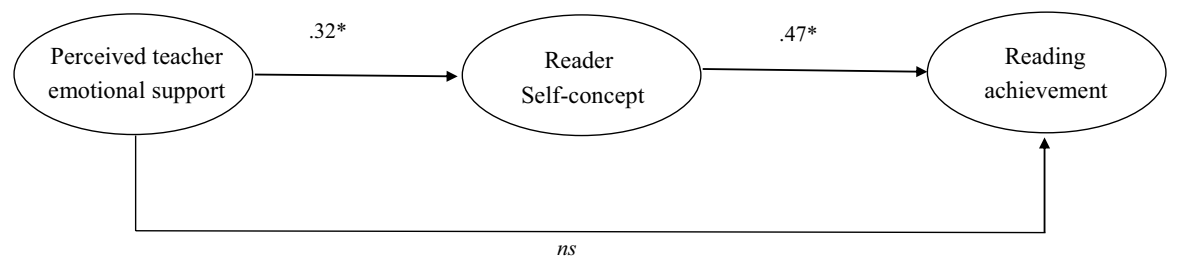

Fig. 2 Associations among perceived teacher emotional support, reader self-concept and reading achievement $\left(\chi^{2}=167.710 ; d f=32\right.$; RMSEA $\left.=.038, \mathrm{CFI}=.975, \mathrm{NFI}=.964, \mathrm{IFI}=.970\right) .{ }^{*} p<.001, n s$ non-significant. $\mathrm{n}=2888$ 
RMSEA $=.039, \mathrm{CFI}=.970, \mathrm{NFI}=.964 \mathrm{IFI}=.970$ ). Thus, Hypothesis 4 was partially supported.

\section{Discussion}

In the current study, we investigated cross-sectional associations between perceived emotional support from teacher, reader self-concept, and reading achievement among 2888 children from 150 classes in 150 schools. The results supported a hypothesized association between reader self-concept and reading achievement. However, we did not find any significant direct association between perceived teacher emotional support and reading achievement, although we found a significant direct association between perceived teacher emotional support and reader selfconcept. Furthermore, reader self-concept fully mediated the association between perceived teacher emotional support and reading achievement.

As referred to previously, our theoretical approach when studying the relation between reader self-concept and reading achievement was based on the selfenhancement model (Marsh 1990). The association between reader self-concept and reading achievement was consistent with our expectations. Associations between reader self-concept and reading achievement found in previous studies (Chapman et al. 2000; Marsh and Martin 2011) was also confirmed in our study. However, it is worth noting that the cross-sectional design of our study did not allow us to determine whether reader self-concept causes reading achievement. Moreover, recently, it has been acknowledged that an either/or perspective with regard to the self-enhancement model (Marsh 1990), and the skill-development model (Calsyn and Kenny 1977; Scheirer and Kraut 1979) is too simplistic. A growing body of research supports a reciprocal effects model approach, where academic self-concept both influences and is influenced by academic achievement (Marsh 2006; Marsh et al. 1999; Marsh and Craven 2006; Marsh and Martin 2011; Walgermo et al. 2017). Unfortunately, due to our cross-sectional design, investigating reciprocal effects between reader self-concept and reading achievement was not possible at this stage of our study.

Further, we found a positive direct association between perceived teacher emotional support and reader self-concept. This finding is in line with theory on socialisation-motivational processes, which states that individuals construct beliefs about themselves based on their experiences and interactions with others (Weiner 1993) and gives support to researchers who have emphasized the importance of closeness and care in the teacher-student relationship (Goldstein 1999; Lynch and Cicchetti 1997; Pianta 1994; Wentzel 1997).

Based on previous research, we also expected to find a direct relation between perceived teacher emotional support and reading achievement (see, e.g., Curby et al. 2013a, 2009; Furrer and Skinner 2003; Hamre and Pianta 2001, 2005; Hughes et al. 2008; Rudasill et al. 2010), but this hypothesized association was not supported. Despite the lack of direct association between perceived teacher emotional support and reading achievement, the results revealed a full mediation between perceived teacher emotional support and reading achievement through reader self-concept. 
Specifically, this implies that students who perceive their teacher as emotional supportive, have a stronger reader self-concept, which again is an important determinant of reading achievement. Additionally, this finding is line with the theory of socialmotivational processes, which emphasize that the social world of students influences academic outcomes primarily through intrapersonal and psychological processes (Wentzel 1999). Moreover, our finding suggests that a careful approach that is sensitive to the emotional needs of the child is probably beneficial not only for the social development of the child, but also for the development of learning through stimulating the self-concept. The significance of reader self-concept in the relation between perceived teacher emotional support and reading achievement is an interesting finding, and suggests that this relations is more complex than suggested previously.

The reliability of individual students' perceptions of their learning environment has been questioned due to the idiosyncratic nature of students' perceptions of the learning environment in a given class (Aleamoni 1999; Marsh and Roche 1997). Perhaps as a result of this, earlier studies on teacher emotional support have primarily relied on the use of observational studies or teacher ratings. However, in the present study, we take a different approach and argue that student perceptions are valuable and reliable sources when studying teacher emotional support. Moreover, we found that perceived teacher emotional support is more adequately measured at the individual level rather than the class level. Downer et al. (2015) investigated dimensions of teacher emotional support on a sample size of 50 classes and found that only a small amount of the variability could be attributed to the classroom level. However, a sample size of 50 is generally set as a minimum criterion for multi-level analysis of student reports (Marsh et al. 2012). Therefore, an obvious strength of our study is that we included a large number of classes $(n=150)$ to make more powerful interpretations. Interestingly, despite the increased number of classes, the variability between classes regarding perceived teacher emotional support is still quite low. This finding is line with theory suggesting that teachers approach and treat children differently (Pianta et al. 1995; Skaalvik and Skaalvik 2013), and contributes significantly to the current research on teacher emotional support. As referred to previously, to our knowledge, perceptual measures of emotional support have not been applied in previous studies on children at such a young age, and in light of this, the current study makes an important contribution to the research field.

\subsection{Limitations and future research}

The present study has some limitations. First, the study was cross-sectional, meaning we cannot draw causal inferences concerning the hypothesized relationships. Perhaps children who have better reading skills develop a higher self-concept, in line with the skill-development model. As a result, teachers might be emotionally more supportive of these children. This means that a possible dominant causal direction between variables should be further investigated using longitudinal designs.

Second, some of our measures were based on self-reports, which can increase the problem of common method variance. It has been suggested that to reduce the problem of common method variance, the dependent and independent variables should 
be obtained from different sources (Podsakoff and Organ 1986). In our study, the measure of reading skills was derived from validated tests rather than self-reports, which might reduce the problem of common method variance. Finally, the study was conducted on children in a Norwegian school context; therefore, caution should be taken when generalizing the results. However, the large sample is certainly a strength of our study, as it enhances the generalizability of the findings. Still, it would be valuable if future studies could examine the same associations also in different contexts.

\subsection{Conclusion and implications}

Prior research has shown that early reading is an important determinant of further academic achievement and success (Chapman et al. 2000; Perfetti and Curtis 1986; Perie et al. 2005). Consequently, it is important to understand what factors contribute to reading achievement. The current study provides evidence that emotional support from the teacher is a significant factor in this respect. Although emotional support from the teacher did not relate directly to reading achievement, is still related indirectly to reading achievement through reader self-concept.

The current study may have several practical implications. First, teachers should keep in mind that supporting the children emotionally will contribute not only to better relationships with the child, but also to higher reader self-concept and ultimately better reading performance. Second, considering early reading is an important determinant of academic achievement in later years, teachers play a significant role not only in the development of reading skills of the child, but also in the child's academic development in general. Third, teachers should be aware of whether they favour some children over others, thereby paying more attention to their needs. For instance, teachers might consider the children with high reading skills to be more favourable, and thereby pay more attention to their emotional needs compared to other children with lower reading skills. Finally, schools and teacher education programs in general should not focus solely on subjects and teaching skills as aspects of the teacher profession, but also on training teachers in how to best relate to children so they feel appreciated and respected in the classroom.

\section{Compliance with ethical standards}

Conflict of interest The authors declare that they have no conflict of interest.

Open Access This article is distributed under the terms of the Creative Commons Attribution 4.0 International License (http://creativecommons.org/licenses/by/4.0/), which permits unrestricted use, distribution, and reproduction in any medium, provided you give appropriate credit to the original author(s) and the source, provide a link to the Creative Commons license, and indicate if changes were made. 


\section{References}

Aleamoni, L. M. (1999). Student rating myths versus research facts from 1924 to 1998. Journal of Personnel Evaluation in Education, 13(2), 153-166.

Arbuckle, J. L. (2014). IBM SPSS AMOS 23 user's guide [Computer program]. Crawfordville, FL: Amos Development Corporation.

Barbaranelli, C., Lee, C. S., Vellone, E., \& Riegel, B. (2015). The problem with Cronbach's alpha: Comment on Sijtsma and van der Ark (2015). Nursing Research, 64(2), 140-145.

Bentler, P. M., \& Bonett, D. G. (1980). Significance tests and goodness of fit in the analysis of covariance structures. Psychological Bulletin, 88(3), 588-606.

Bentler, P. M., Jackson, D. N., \& Messick, S. (1971). Identification of content and style: A two dimensional interpretation of acquiescence. Psychological Bulletin, 76, 186-204.

Bliese, P. D. (2000). Within-group agreement, non-independence, and reliability: Implications for data aggregation and analysis. In K. J. Klein \& S. W. J. Kozlowski (Eds.), Multilevel theory, research, and methods in organizations: Foundations, extensions, and new directions (pp. 349-381). San Francisco: Jossey-Bass.

Bong, M., \& Clark, R. E. (1999). Comparison between self-concept and self-efficacy in academic motivation research. Educational Psychologist, 34(3), 139-153.

Bredekamp, S., \& Copple, C. (1997). Developmentally appropriate practice in early childhood education (Revised ed.). Washington, DC: National Association for the Education of Young Children.

Burchinal, M., Howes, C., Pianta, R. C., Bryant, D., Early, D., Clifford, E., et al. (2008). Predicting child outcomes at the end of kindergarten from the quality of pre-kindergarten teaching, instruction, activities, and caregiver sensitivity. Applied Developmental Science, 12(3), 140-153.

Byrne, B. M. (1984). The general/academic self-concept nomological network: A review of construct validation research. Review of Educational Research, 54(3), 427-456.

Byrne, B. M. (1996). Measuring self-concept across the life span: Issues and instrumentation. Washington, DC: American Psychological Association.

Calsyn, R. J., \& Kenny, D. A. (1977). Self-concept of ability and perceived evaluation of others: Cause or effect of academic achievement? Journal of Educational Psychology, 69(2), 136-145.

Chapman, J. W., \& Tunmer, W. E. (1995). Development of young children's reading self-concepts: An examination of emerging subcomponents and their relationship with reading achievement. Journal of Educational Psychology, 87(1), 154-167.

Chapman, J. W., \& Tunmer, W. E. (1997). A longitudinal study of beginning reading achievement and reading self-concept. British Journal of Educational Psychology, 67(3), 279-291.

Chapman, J. W., Tunmer, W. E., \& Prochnow, J. E. (2000). Early reading-related skills and performance, reading self-concept, and the development of academic self-concept: A longitudinal study. Journal of Educational Psychology, 92(4), 703-708.

Curby, T. W., Brock, L. L., \& Hamre, B. K. (2013a). Teachers' emotional support consistency predicts children's achievement gains and social skills. Early Education \& Development, 24(3), 292-309.

Curby, T. W., Rimm-Kaufman, S. E., \& Abry, T. (2013b). Do emotional support and classroom organization earlier in the year set the stage for higher quality instruction? Journal of School Psychology, 51(5), 557-569.

Curby, T. W., Rimm-Kaufman, S. E., \& Ponitz, C. C. (2009). Teacher-child interactions and children's achievement trajectories across kindergarten and first grade. Journal of Educational Psychology, 101(4), 912-925.

Downer, J. T., Stuhlman, M., Schweig, J., Martínez, J. F., \& Ruzek, E. (2015). Measuring effective teacher-student interactions from a student perspective: A multi-level analysis. The Journal of Early Adolescence, 35(5-6), 722-758.

Eccles, J., Wigfield, A., Harold, R. D., \& Blumenfeld, P. (1993). Age and gender differences in children's self-and task perceptions during elementary school. Child Development, 64(3), 830-847.

Fraser, B. J. (1989). Twenty years of classroom climate work: Progress and prospect. Journal of Curriculum Studies, 21(4), 307-327.

Furrer, C., \& Skinner, E. (2003). Sense of relatedness as a factor in children's academic engagement and performance. Journal of Educational Psychology, 95(1), 148-162.

Goldstein, L. S. (1999). The relational zone: The role of caring relationships in the co-construction of mind. American Educational Research Journal, 36(3), 647-673. 
Grusec, J. E., \& Goodnow, J. J. (1994). Impact of parental discipline methods on the child's internalization of values: A reconceptualization of current points of view. Developmental Psychology, 30(1), 4-19.

Guay, F., Marsh, H. W., \& Boivin, M. (2003). Academic self-concept and academic achievement: Developmental perspectives on their causal ordering. Journal of Educational Psychology, 95(1), 124-136.

Hamre, B. K., \& Pianta, R. C. (2001). Early teacher-child relationships and the trajectory of children's school outcomes through eighth grade. Child Development, 72(2), 625-638.

Hamre, B. K., \& Pianta, R. C. (2005). Can instructional and emotional support in the first-grade classroom make a difference for children at risk of school failure? Child Development, 76(5), 949-967.

Hamre, B. K., \& Pianta, R. C. (2007). Learning opportunities in preschool and early elementary classrooms. In R. C. Pianta, M. J. Cox, \& K. L. Snow (Eds.), School readiness and the transition to kindergarten in the era of accountability (pp. 49-83). Baltimore: Paul H Brookes Publishing.

Harter, S., \& Connell, J. (1984). A comparison of alternative models of the relationships between academic achievement and children's perceptions of competence, control, and motivational orientation. In J. Nicholls (Ed.), The development of achievement-related cognitions and behaviors (pp. 219250). Greenwich, CT: JAI Press.

Helmke, A., \& van Aken, M. A. (1995). The causal ordering of academic achievement and self-concept of ability during elementary school: A longitudinal study. Journal of Educational Psychology, 87(4), 624-637.

Hu, L., \& Bentler, P. M. (1999). Cutoff criteria for fit indexes in covariance structure analysis: Conventional criteria versus new alternative. Structural Equation Modeling, 1, 1-55.

Hughes, J. N., Luo, W., Kwok, O.-M., \& Loyd, L. K. (2008). Teacher-student support, effortful engagement, and achievement: A 3-year longitudinal study. Journal of Educational Psychology, 100(1), $1-14$.

Hymel, S., Comfort, C., Schonert-Reichl, K., \& McDougall, P. (1996). Academic failure and school dropout: The influence of peers. In J. Juvonen \& K. R. Wentzel (Eds.), Social motivation: Understanding children's school adjustment (pp. 313-345)., Cambridge studies in social and emotional development New York: Cambridge University Press.

Jöreskog, K. G. (1993). Testing structural equation models. In K. A. Bollen \& J. S. Long (Eds.), Testing structural equation models (pp. 294-316). Newbury Park: Sage.

Kern, L., \& Clemens, N. H. (2007). Antecedent strategies to promote appropriate classroom behavior. Psychology in the Schools, 44(1), 65-75.

Ladd, G. W., Birch, S. H., \& Buhs, E. S. (1999). Children's social and scholastic lives in kindergarten: Related spheres of influence? Child Development, 70(6), 1373-1400.

LeBreton, J. M., \& Senter, J. L. (2008). Answers to 20 questions about interrater reliability and interrater agreement. Organizational Research Methods, 11(4), 815-852.

Loehlin, J. C., \& Beaujean, A. A. (2016). Latent variable models: An introduction to factor, path, and structural equation analysis. Milton Park: Routledge.

Lüdtke, O., Robitzsch, A., Trautwein, U., \& Kunter, M. (2009). Assessing the impact of learning environments: How to use student ratings of classroom or school characteristics in multilevel modeling. Contemporary Educational Psychology, 34(2), 120-131.

Lüdtke, O., Trautwein, U., Kunter, M., \& Baumert, J. (2006). Reliability and agreement of student ratings of the classroom environment: A reanalysis of TIMSS data. Learning Environments Research, 9(3), 215-230.

Lynch, M., \& Cicchetti, D. (1997). Children's relationships with adults and peers: An examination of elementary and junior high school students. Journal of School Psychology, 35(1), 81-99.

MacKinnon, D. P., Lockwood, C. M., \& Williams, J. (2004). Confidence limits for the indirect effect: Distribution of the product and resampling methods. Multivariate Behavioral Research, 39, 99-128.

Marsh, H. W. (1990). Causal ordering of academic self-concept and academic achievement: A multiwave, longitudinal panel analysis. Journal of Educational Psychology, 82(4), 646-656.

Marsh, H. W. (1993). Academic self-concept: Theory, measurement, and research. In J. M. Suls (Ed.), Psychological perspectives on the self (Vol. 4, pp. 59-98)., The self in social perspective Hillsdale, NJ: Lawrence Erlbaum Associates.

Marsh, H. W. (2006). Self-concept theory, measurement and research into practice: The role of self-concept in educational psychology. Leicester: British Psychological Society.

Marsh, H. W., Byrne, B. M., \& Yeung, A. S. (1999). Causal ordering of academic self-concept and achievement: Reanalysis of a pioneering study and revised recommendations. Educational Psychologist, 34(3), 155-167. 
Marsh, H. W., \& Craven, R. G. (2006). Reciprocal effects of self-concept and performance from a multidimensional perspective: Beyond seductive pleasure and unidimensional perspectives. Perspectives on Psychological Science, 1(2), 133-163.

Marsh, H. W., Lüdtke, O., Nagengast, B., Trautwein, U., Morin, A. J., Abduljabbar, A. S., et al. (2012). Classroom climate and contextual effects: Conceptual and methodological issues in the evaluation of group-level effects. Educational Psychologist, 47(2), 106-124.

Marsh, H. W., \& Martin, A. J. (2011). Academic self-concept and academic achievement: Relations and causal ordering. British Journal of Educational Psychology, 81(1), 59-77.

Marsh, H. W., \& Roche, L. A. (1997). Making students' evaluations of teaching effectiveness effective: The critical issues of validity, bias, and utility. American Psychologist, 52(11), 1187-1197.

Marsh, H. W., \& Shavelson, R. (1985). Self-concept: Its multifaceted structure. Educational Psychologist, 20(3), 107-123.

Mashburn, A. J., Pianta, R. C., Hamre, B. K., Downer, J. T., Barbarin, O. A., Bryant, D., et al. (2008). Measures of classroom quality in prekindergarten and children's development of academic, language, and social skills. Child Development, 79(3), 732-749.

Merritt, E. G., Wanless, S. B., Rimm-Kaufman, S. E., Cameron, C., \& Peugh, J. L. (2012). The contribution of teachers' emotional support to children's social behaviors and self-regulatory skills in first grade. School Psychology Review, 41(2), 141-159.

Muthen, B. O., \& Satorra, A. (1995). Complex data sampling in structural equation modeling. Sociological Methodology, 25, 297-316.

Nunnally, J. (1978). Psychometric theory (2nd ed.). New York: McGraw-Hill.

O'Connor, E., \& McCartney, K. (2007). Examining teacher-child relationships and achievement as part of an ecological model of development. American Educational Research Journal, 44(2), 340-369.

Pajares, F., \& Schunk, D. H. (2001). Self-beliefs and school success: Self-efficacy, self-concept, and school achievement. In R. Riding \& S. Rayner (Eds.), Perception (pp. 239-266). London: Alex Publishing.

Pallas, A. M., Entwisle, D. R., Alexander, K. L., \& Cadigan, D. (1987). Children who do exceptionally well in first grade. Sociology of Education, 60(4), 257-271.

Perfetti, C., \& Curtis, M. (1986). Development of children's reading self-concepts and their relationship with reading achievement. Journal of Educational Psychology, 87, 155-169.

Perie, M., Grigg, W., \& Donahue, P. (2005). The Nation's Report Card [TM]: Reading, 2005. NCES 2006-451. National Center for Education Statistics.

Perry, K. E., Donohue, K. M., \& Weinstein, R. S. (2007). Teaching practices and the promotion of achievement and adjustment in first grade. Journal of School Psychology, 45(3), 269-292.

Peugh, J. L. (2010). A practical guide to multilevel modeling. Journal of School Psychology, 48, 85-112.

Pianta, R. C. (1994). Patterns of relationships between children and kindergarten teachers. Journal of School Psychology, 32(1), 15-31.

Pianta, R. C., Belsky, J., Vandergrift, N., Houts, R., \& Morrison, F. J. (2008a). Classroom effects on children's achievement trajectories in elementary school. American Educational Research Journal, 45(2), 365-397.

Pianta, R. C., La Paro, K. M., \& Hamre, B. K. (2008b). Classroom assessment scoring system ${ }^{\mathrm{TM}}$ : Manual $K$-3. Baltimore, MD, US: Paul H Brookes Publishing.

Pianta, R. C., Steinberg, M. S., \& Rollins, K. B. (1995). The first two years of school: Teacher-child relationships and deflections in children's classroom adjustment. Development and Psychopathology, $7(2), 295-312$.

Pianta, R. C., \& Stuhlman, M. W. (2004). Teacher-child relationships and children's success in the first years of school. School Psychology Review, 33(3), 444-458.

Podsakoff, P. M., \& Organ, D. W. (1986). Self-reports in organizational research: Problems and prospects. Journal of Management, 12(4), 531-544.

Raudenbush, S. W., \& Bryk, A. S. (2002). Hierarchical linear models: Applications and data analysis methods (Vol. 1). Sage: University of Chicago.

Rimm-Kaufman, S. E., \& Chiu, Y. J. I. (2007). Promoting social and academic competence in the classroom: An intervention study examining the contribution of the responsive classroom approach. Psychology in the Schools, 44(4), 397-413.

Rudasill, K. M., Gallagher, K. C., \& White, J. M. (2010). Temperamental attention and activity, classroom emotional support, and academic achievement in third grade. Journal of School Psychology, 48(2), 113-134. 
Scheirer, M. A., \& Kraut, R. E. (1979). Increasing educational achievement via self-concept change. Review of Educational Research, 49(1), 131-149.

Seymour, P. H., Aro, M., \& Erskine, J. M. (2003). Foundation literacy acquisition in European orthographies. British Journal of Psychology, 94(2), 143-174.

Shavelson, R. J., Hubner, J. J., \& Stanton, G. C. (1976). Self-concept: Validation of construct interpretations. Review of Educational Research, 46(3), 407-441.

Sijtsma, K. (2009). On the use, the misuse, and the very limited usefulness of Cronbach's alpha. Psychometrika, 74(1), 107-120.

Skaalvik, E. M., \& Hagtvet, K. A. (1990). Academic achievement and self-concept: An analysis of causal predominance in a developmental perspective. Journal of Personality and Social Psychology, 58(2), 292-307.

Skaalvik, E. M., \& Skaalvik, S. (2013). School goal structure: Associations with students' perceptions of their teachers as emotionally supportive, academic self-concept, intrinsic motivation, effort, and help seeking behavior. International Journal of Educational Research, 61, 5-14.

Solheim, O. J., Rege, M., \& McTigue, E. (2017). Study protocol: “Two teachers" a randomized controlled trial investigating individual and complementary effects of teacher-student ratio in literacy instruction and professional development for teachers. International Journal of Educational Research, 86, 122-130.

Spear-Swerling, L., \& Sternberg, R. J. (1996). Off track: When poor readers become learning disabled. Boulder, CO: Westview Press.

Steinberg, L., Darling, N. E., \& Fletcher, A. C. (1995). In P. Moen, G. H. Elder Jr., \& K. Lüscher (Eds.), Examining lives in context: Perspectives on the ecology of human development (pp. 423-466).

Stipek, D. J. (2002). Motivation to learn: From theory to practice (4th ed.). Needham Heights, MA: Allyn \& Bacon.

Stipek, D., \& Byler, P. (2004). The early childhood classroom observation measure. Early Childhood Research Quarterly, 19(3), 375-397.

Stuhlman, M. W., \& Pianta, R. C. (2009). Profiles of educational quality in first grade. The Elementary School Journal, 109(4), 323-342.

Torgesen, J. K., Rashotte, C. A., \& Wagner, R. K. (1999). TOWRE: Test of word reading efficiency. Austin, TX: Pro-ed.

Wagner, W., Göllner, R., Helmke, A., Trautwein, U., \& Lüdtke, O. (2013). Construct validity of student perceptions of instructional quality is high, but not perfect: Dimensionality and generalizability of domain-independent assessments. Learning and Instruction, 28, 1-11.

Walgermo, B., Foldnes, N., Uppstad, P. H., \& Solheim, O. J. (2017). Developmental dynamics of early reading skill, literacy interest and reader self-concept within the first year of formal schooling. Reading and Writing, 31(6), 1379-1399.

Walgermo, B., Frijters, J. C., \& Solheim, O. J. (2018). Literacy interest and reader self-efficacy when formal reading introduction begins. Early Childhood Research Quarterly, 44(3), 90-100.

Weiner, B. (1993). On sin versus sickness: A theory of perceived responsibility and social motivation. American Psychologist, 48(9), 957-965.

Wentzel, K. R. (1997). Student motivation in middle school: The role of perceived pedagogical caring. Journal of Educational Psychology, 89(3), 411-419.

Wentzel, K. R. (1999). Social-motivational processes and interpersonal relationships: Implications for understanding motivation at school. Journal of Educational Psychology, 91(1), 76-97.

Wigfield, A., \& Karpathian, M. (1991). Who am I and what can I do? Children's self-concepts and motivation in achievement situations. Educational Psychologist, 26(3-4), 233-261.

Maria Therese Jensen has a Ph.D. in Psychology, and is currently working as a post doctor/associate professor at The Norwegian Reading Centre, University of Stavanger, Norway. Her main research field includes organisational and occupational health psychology, teacher burnout, classroom emotional climate, teacher emotional support, and reading abilities.

Oddny Judith Solheim is an Associate Professor at the Norwegian Reading Centre, University of Stavanger, Norway. Her research fields includes assessment of reading, reading difficulties and social-motivational processes related to reading development. 
Ella Maria Cosmovici Idsøe is Professor in psychology at the Norwegian Center for Science Education, University of Oslo, Norway. Her main research interests focuses on the education of the gifted children, bullying and consequences of bullying, children with social and emotional problems. 